\title{
VALIDATION OF HADLOCK'S AND SHEPARD FORMULAE OF FETAL WEIGHT ESTIMATION IN EASTERN REGION OF NEPAL
}

\author{
Khadka $R^{1^{*}}$
}

\section{Affiliation}

1. Lecturer, Department of Radiodiagnosis, Birat Medical College and Teaching Hospital

\section{ARTICLE INFO}

Article History

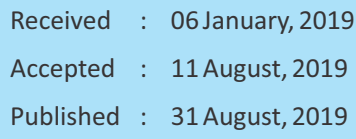

Received : 06 January, 2019

Accepted : 11 August, 2019

Published : 31 August, 2019

(C) Authors retain copyright and grant the journal right of first publication with the work simultaneously licensed under Creative Commons Attribution License CC - BY 4.0 that allows others to share the work with an acknowledgment of the work's authorship and initial publication in this journal.

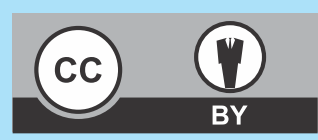

ORA 124

DOI: http://dx.doi.org/10.3126/bjhs.v4i2.25457

* Corresponding Author

Dr. Roshana Khadka

Lecturer

Department of Radiodiagnosis

Birat Medical College and Teaching Hospital

Email ID: khadka_roshana@hotmail.com ORCID ID: http://orcid.org/0000-0003-4301-8406

\section{Citation}

Khadka R, Validation of Hadlock's and Shepard Formulae of Fetal Weight Estimation In Eastern Region of Nepal. BJHS 2019;4(2)9: 738 - 743.

\section{ABSTRACT}

\section{Introduction}

Ultrasonography plays a pivotal role in present day obstetrics. It has been well recognized that the fetuses of extremes of the normal birth weight range are associated with increased perinatal morbidity, mortality and adverse development outcomes. Categorization of fetal weight into either the small or large for gestational age may lead to timed obstetric interventions that collectively represent significant departure from routine antenatal care.

\section{Objective}

To compare the accuracy of Hadlock's 1, 2, 3, 4 and Shepard model in estimating expected fetal weight and its comparison with actual birth weight in our population at eastern region of Nepal.

\section{Methodology}

A prospective observational study was performed in the Department of Radiodiagnosis, Nobel Medical college and teaching hospital, Biratnagar, over a period of 6 months dated Jan 2018 to June 2018 using systematic random sampling with sample size estimated as 160 , with $5 \%$ level of significance, $80 \%$ power of test and a maximum of 200 grams differences by our predicting model from actual mean weight. Singleton, term pregnancy (37- 42 weeks gestational age) verified with antenatal USG performed prior to 20 weeks' gestation. Pregnancies complicated by congenital anomalies and deliveries after 2 days of USG examination were excluded.

\section{Results}

159 pregnant ladies were enrolled in our study with mean age of $27.60 \pm 5.633$ years (range $18-43$ years). The average (actual) birth weight recorded was $3450.79 \pm 438.73 \mathrm{gms}$. The different formulae for estimating birth weight gave us similar results. Estimation of fetal weight by Shepard gave us a mean of 3340.80 \pm 463.72. Hadlock1, Hadlock2, Hadlock3 and Hadlock4were $3546.55 \pm 429.92$ grams, $3491.18 \pm 439.49$ grams, 3445.23 \pm 422.79 grams, and $3446.12 \pm 418.43$ grams respectively.

\section{Conclusion}

All four Hadlock formulae gave comparable results for fetal weight estimation including the Shepard formula; however, Shepard formula tends to underestimate fetal weight as compared to rest of the formulae. Among the Hadlock's, Hadlock 2 seems to show better accuracy in fetal weight prediction in our population of study. The mean birth weight recorded using Hadlock 1 formula gave the beer correlation with the actual birth weight though the difference between four Hadlock formulae was all insignificant.

\section{KEYWORDS}

birth weight, fetal weight, ultrasonography 


\section{INTRODUCTION}

Accurate pre delivery assessment and estimation of fetal weight is important in many obstetrics situations. ${ }^{1}$ Fetuses at extremes of normal birth weight range are associated with increased perinatal morbidity, mortality and adverse development outcomes. ${ }^{2}$ Further, macrosomic infants have a six fold increased risk of birth trauma. ${ }^{3}$ Categorization of fetal weight into either the small or large for gestational age helps in timely obstetric interventions. ${ }^{4}$ Ultrasound models using combination of various fetal parameters like head measurements (biparietal diameter or head circumference), abdominal circumference (AC), femur length (FL) and trunk circumference yield more accuracy. ${ }^{5,6}$ Different models have been formulated for fetal weight estimation using different combinations of fetal biometric parameters; but most of these models have been derived from western population data. $^{7-9 .}$ Fetuses tend to gain some weight in utero from the day of scan till date of delivery. ${ }^{10}$ Various researches were done to find out the best time to document ultrasonically derived fetal weight and a recent study identified that the results were better for the calculated birth weight within 3 days of delivery ${ }^{11}$ There is no general consensus as to which model gives a better validity in predicting birth weight in particular race or ethnicity. Birth weight estimation models derived from one ethnic population applied to another population might result in erroneous estimations, therefore, judicious selection of appropriate models for the local population is important to ensure precision in the assessment. The aim of our study was to compare the accuracy of Hadlock's 1, 2, 3, 4 and Shepard model in estimating expected fetal weight and its comparison with actual birth weight in our population at eastern region of Nepal.

\section{METHODOLOGY}

An analytical study was performed in the department of Radiology and department of Obstetrics Nobel Medical College and teaching hospital, Biratnagar, for a period of 6months dated Jan 2018 to June 2018 using Systematic random sampling with sample size estimated as 160, with $5 \%$ level of significance, $80 \%$ power of test and a maximum of 200 grams differences by our predicting model from actual mean weight. Ethical clearance was obtained and consent of the patients were taken before conducting the study. All Singleton term pregnancies (37- 42 weeks gestational age) were included and pregnancies complicated by congenital anomalies and deliveries after 3 days of USG examination were excluded from the study. The relevant fetal parameters viz. biparietal diameter, head circumference, femur length and abdominal circumference were recorded using Samsung ultrasound machine with a 3.5 $\mathrm{MHz}$ curvilinear probe and fetal weights entered for each formula.

Biparietal diameter (BPD) was measured on a real time ultrasound machine in a transverse plane over the frozen image from the outer edge of the proximal skull to the inner edge of the distal skull table, with electronic calipers placed on a line perpendicular to the mid line echo.

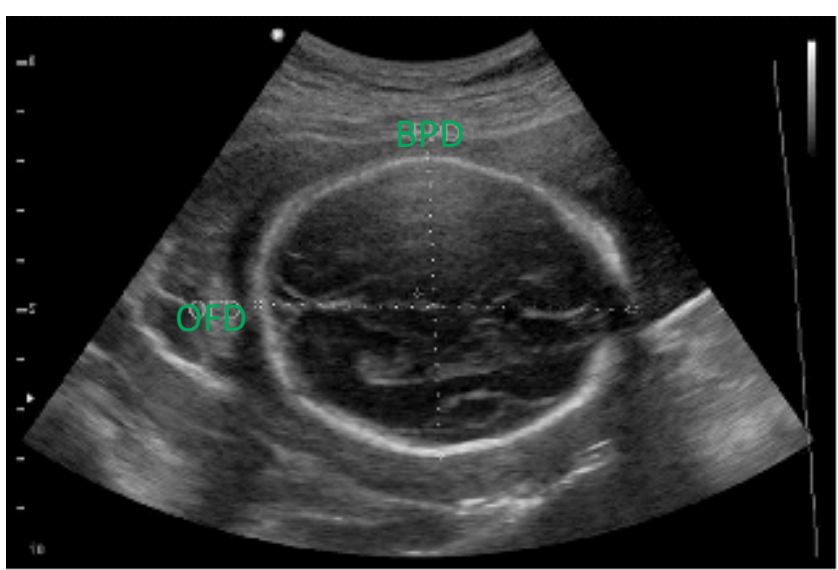

Figure 1: Measurement of biparietal diameter (BPD)

Head circumference (HC) was measured on a real time ultrasound machine at the same section as above using ellipse method by tracing the head circumference along the outer skull table.

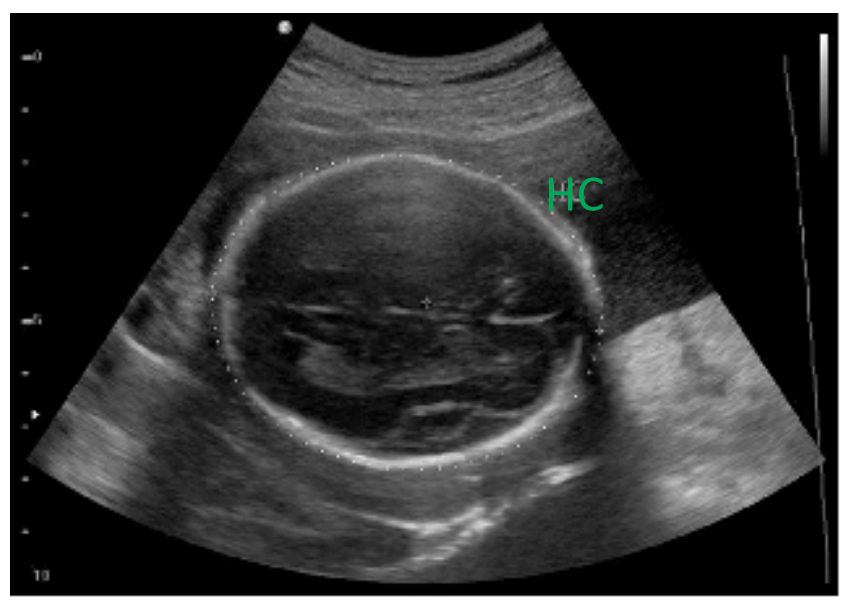

Figure 2: Measurement of Head circumference (HC)

Abdominal circumference (AC) was measured on a real time ultrasound machine at the level of umbilical vein as it enters the left portal vein. Stomach bubble was also taken as landmark. It was measured using ellipse method.

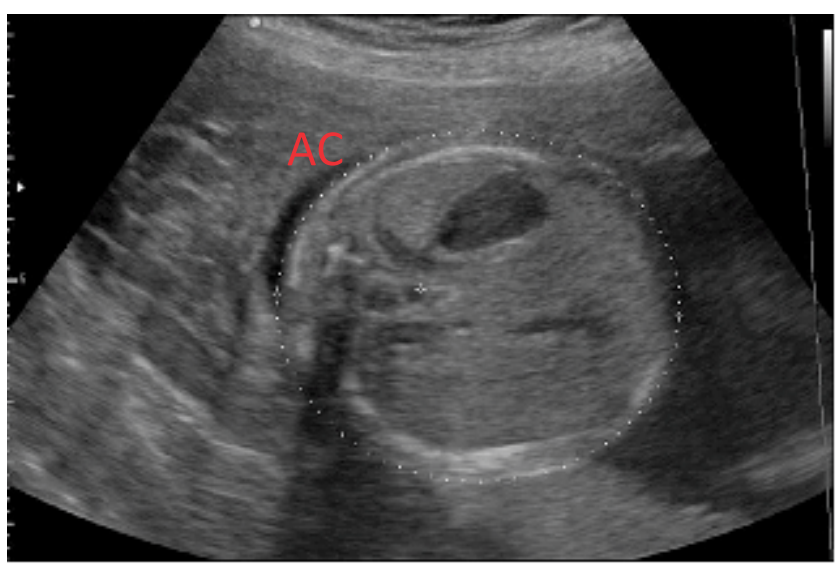

Figure 3: Measurement of abdominal circumference (AC)

Femur Length (FL) was measured on a real time ultrasound machine from greater trochanter to external condyle, excluding femoral head. 


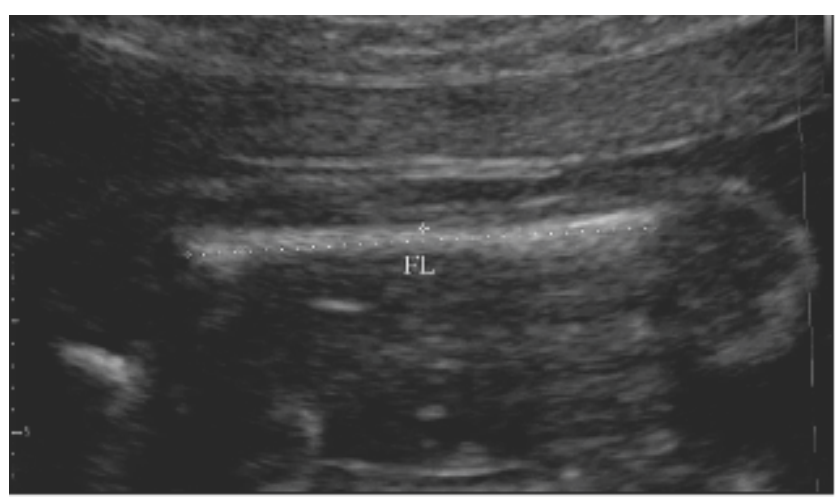

Figure 4: Measurement of femur length (FL)

The estimated fetal weight was obtained using the following parameters vizBPD, HC, AC, FL, which were applied to the under mentioned formulae, and entered in Microsoft excel.

The formulae given for the models are:

\section{HADLOCK1FORMULA:}

$\operatorname{LogFW}(g)=1.304+(0.05281 x A C)+(0.1938 x F L)-(0.004 x$ AC $x$ FL)

HADLOCK2FORMULA:LogFW(g)=1.335-(0.0034xACxFL) + $(0.0316 \times B P D)+(0.0457 \times A C)+(0.1623 \times \mathrm{FL})$

HADLOCK3 FORMULA:LogFW(g)=1.326-(0.00326xACxFL) $+(0.0107 \times \mathrm{HC})+(0.0438 \times A C)+(0.158 \times \mathrm{FL})$

HADLOCK4FORMULA:LogFW(g) $=0.3596+(0.00061 X B P D X$ $A C)+(0.0424 X A C)+(0.174 X F L)+(0.0064 X H C)-(0.00386$ XACXFL)

SHEPARD FORMULA:LOgFW $(g)=-1.7492+(0.166 \times$ $B P D)+(0.046 \times A C)-(0.002646 \times A C \times$ BPD $) \times 1000$

Respective expected fetal weight was calculated and the actual birth weight of the baby was recorded within 15 minutes post-delivery on a baby scale. The actual weight of the neonate was then compared to ultrasound predicted birth weight. Collected data were entered and analyzed using SPSS 15.0. The comparison between different formulae for predicting birth weight by USG was performed. Pearson's correlation test was used to see the relation between predicted birth weight and the actual birth weight. A p-value less than 0.05 were considered significant.

\section{RESULTS}

159 pregnant ladies were enrolled in our study with mean age of $27.60 \pm 5.633$ years (range $18-43$ years).

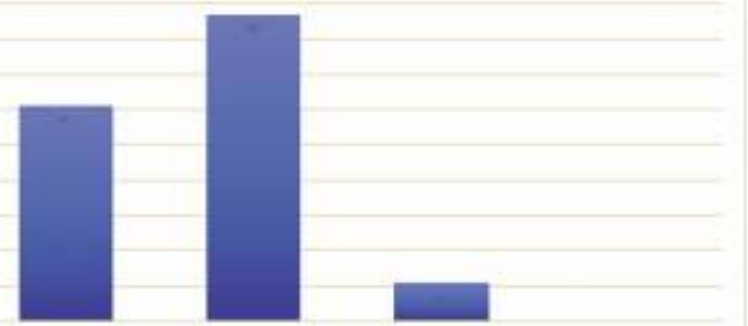

The average (actual) birth weight recorded was 3450.79 \pm 438.73gms. The different formulae for estimating birth weight gave us similar results. The mean estimated fetal weight by Shepard model was $3340.80 \pm 463.72$ and by Hadlock1, Hadlock2, Hadlock3, Hadlock4 were $3546.55 \pm 429.92,3491.18 \pm 439.49,3445.23 \pm 422.79$, and $3446.12 \pm 418.43$ respectively.

\begin{tabular}{|c|c|c|c|c|}
\hline & $\begin{array}{l}\text { Minimum } \\
\text { Estimated } \\
\text { fetal } \\
\text { weight }\end{array}$ & $\begin{array}{c}\text { Maximum } \\
\text { Estimated } \\
\text { fetal } \\
\text { weight }\end{array}$ & $\begin{array}{c}\text { Mean } \\
\text { Estimated } \\
\text { fetal } \\
\text { weight }\end{array}$ & $\begin{array}{l}\text { Std. Deviation } \\
\text { of estimated } \\
\text { fetal weight }\end{array}$ \\
\hline Hadlock1 & 2546 & 4417 & 3549.55 & 429.924 \\
\hline Hadlock2 & 2447 & 4376 & 3491.18 & 439.485 \\
\hline Hadlock3 & 2490 & 4333 & 3445.23 & 422.787 \\
\hline Hadlock4 & 2455 & 4339 & 3446.12 & 418.425 \\
\hline Shepard & 2179 & 4306 & 3340.80 & 463.724 \\
\hline AFW & 2400 & 4750 & 3450.79 & 438.373 \\
\hline
\end{tabular}

When weights estimated by various formulas were compared with the actual weight it was observed that the estimated weights varied between more than 900 grams of underestimation to more than 800 grams of over estimation in different cases. Further, it was seen that all Hadlock formulae had comparable results whereas Shepard formula tends to underestimate more than the rest, however overestimation was not of much concern with all of the studied formulae.

Table 2 : Distribution of cases by the difference between actual fetal weight and estimated weights by various formulae (Actual - Estimated)

\begin{tabular}{|c|c|c|c|c|c|c|c|c|c|c|}
\hline $\begin{array}{c}\text { Range of } \\
\text { Difference } \\
\text { (Actual Estimated) }\end{array}$ & & dlock1 & & lock2 & & llock3 & $\mathrm{Ha}$ & llock4 & She & pard \\
\hline$\leq-900.00$ & 1 & 0.6 & 1 & 0.6 & 1 & 0.6 & 0 & 0 & 0 & 0 \\
\hline$-899.99-800$ & 0 & 0 & 0 & 0 & 0 & 0 & 1 & 0.6 & 0 & 0 \\
\hline$-799.99-700$ & 1 & 0.6 & 0 & 0 & 0 & 0 & 0 & 0 & 0 & 0 \\
\hline$-699.99-600$ & 3 & 1.9 & 4 & 2.5 & 1 & 0.6 & 3 & 1.9 & 2 & 1.3 \\
\hline$-599.99-500$ & 2 & 1.3 & 0 & 0 & 3 & 1.9 & 1 & 0.6 & 3 & 1.9 \\
\hline$-499.99-400$ & 5 & 3.1 & 6 & 3.8 & 4 & 2.5 & 6 & 3.8 & 4 & 2.5 \\
\hline$-399.99-300$ & 10 & 6.3 & 5 & 3.1 & 3 & 1.9 & 4 & 2.5 & 4 & 2.5 \\
\hline$-299.99-200$ & 17 & 10.7 & 10 & 6.3 & 11 & 6.9 & 9 & 5.7 & 7 & 4.4 \\
\hline$-199.99-100$ & 33 & 20.8 & 22 & 13.8 & 13 & 8.2 & 14 & 8.8 & 11 & 6.9 \\
\hline$-99.99-0$ & 42 & 26.4 & 38 & 23.9 & 30 & 18.9 & 32 & 20.1 & 12 & 7.5 \\
\hline $.01-100.00$ & 30 & 18.9 & 38 & 23.9 & 44 & 27.7 & 36 & 22.6 & 30 & 18.9 \\
\hline $100.01-200.00$ & 9 & 5.7 & 22 & 13.8 & 26 & 16.4 & 29 & 18.2 & 25 & 15.7 \\
\hline $200.01-300.00$ & 3 & 1.9 & 9 & 5.7 & 17 & 10.7 & 16 & 10.1 & 23 & 14.5 \\
\hline $300.01-400.00$ & 1 & 0.6 & 0 & 0 & 2 & 1.3 & 4 & 2.5 & 20 & 12.6 \\
\hline $400.01-500.00$ & 1 & 0.6 & 2 & 1.3 & 2 & 1.3 & 2 & 1.3 & 10 & 6.3 \\
\hline 500.01600 .00 & 0 & 0 & 1 & 0.6 & 1 & 0.6 & 1 & 0.6 & 4 & 2.5 \\
\hline $600.01-700.00$ & 0 & 0 & 0 & 0 & 0 & 0 & 0 & 0 & 1 & 0.6 \\
\hline $700.01-800.00$ & 0 & 0 & 0 & 0 & 0 & 0 & 0 & 0 & 3 & 1.9 \\
\hline $800.01+$ & 1 & 0.6 & 1 & 0.6 & 1 & 0.6 & 1 & 0.6 & 0 & 0 \\
\hline
\end{tabular}


When observed for the range of \pm 200 grams it was observed that the weights estimated by the Hadlock 1 formula gave 115(72.3\%), Hadlock 2 gave 120(75.4\%), Hadlock 3 gave $113(71 \%)$ and Shepard formula gave $78(49 \%)$ cases in this range.

Table 3: Comparison of accuracy among different formulas within a range of 200 grams on each side. Hadlock1 Hadlock2 Hadlock3 Hadlock4 Shepard

$\begin{array}{cccccc}\text { Accurate } & 115 & 120 & 113 & 111 & 78 \\ \text { Inaccurate } & 44 & 39 & 46 & 48 & 81 \\ \text { Total } & 159 & 159 & 159 & 159 & 159\end{array}$

Considering the cases estimated within range of 200 grams as accurate and other cases as inaccurate, there was no significant difference between different formulae, other than Shepard formula giving least accurate measure and Hadlock 2 giving the most accurate measure.

Pearson's correlation analysis was done to find the relationship between actual fetal weight and those measured by the different models. All of these formulae gave good correlation but the highest degree of correlation with $p$ value of $<0.001$ was obsereved with Hadlock's 1 .

Table 3: Comparison of accuracy among different formulas within a range of 200 grams on each side.

\begin{tabular}{cllc} 
S.No. & Model & \multicolumn{1}{c}{ Test } & $\begin{array}{c}\text { Actual Fetal } \\
\text { weight }\end{array}$ \\
1. & Hadlock 1 & $\begin{array}{l}\text { Pearson correlation } \\
\text { p-value }\end{array}$ & 0.876 \\
& & $<0.001$ \\
2 & Hadlock 2 & Pearson correlation & 0.870 \\
& & p-value & $<0.001$ \\
3 & Hadlock 3 & Pearson correlation & 0.871 \\
& & p-value & $<0.001$ \\
4 & Hadlock 4 & Pearson correlation & 0.859 \\
& & p-value & $<0.001$ \\
5 & Shepard & Pearson correlation & 0.827 \\
& & p-value & $<0.001$
\end{tabular}

\section{DISCUSSION}

Estimation of fetal weight using Ultrasonography has a paramount role in the obstetrics practice. Identification of small and large fetus in-utero not only is helpful in determining the route of delivery but also helps in gearing up for better antepartum care. Software is installed in the ultrasound machines containing various formulae derived from one or combination of the multiple fetal biometric parameters and the formula to calculate fetal weight is solely dependent upon the sonographer's choice. Hadlock 1 formula uses femur length (FL) and abdominal circumference (AC). It was found to be a good predictor of birth weight compared to other methods as it makes use of femur length and abdominal measurements which are not altered at term. Hadlock 2 formula uses all the three parameters viz., Biparietal diameter (BPD), Femur length (FL) and Abdominal circumference $(A C)$. Previous studies have shown that greatest accuracy is achieved with the combination of head, abdominal and femur measurements. ${ }^{5,7}$ Hadlock 3 formula uses abdominal circumference (AC), femur length (FL) and head circumference ( $\mathrm{HC}$ ). In cases of preterm, oligohydramnios, premature rupture of membranes, and dolichocephaly, head circumference $(\mathrm{HC})$ was found to be more reliable than biparietal diameter for estimation of fetal weight. ${ }^{27}$ Shepard's formula uses biparietal diameter (BPD) and abdominal circumference $(A C)$ only, so it reflects less upon the actual fetal weight estimation as observed in our study as well. Hadlock 4 formula usesall of the parameters viz. BPD, $\mathrm{AC}$, FLand $\mathrm{HC}$ but this formula was also equally contributory as compared to Hadlock 2 or Hadlock 3 formulae.

A study done in 109 pregnant Caucasian patients showed that the best in utero weight estimates result from the use of models based on head size, abdominal size and femur length. Since the accuracy of these models $(1 \mathrm{SD}=7.5 \%)$ is significantly better than those based on head and body (BPD and $A C)$, routine use of such models has been recommended ${ }^{6}$ Different formulae yield different expected birth weight therefore it is imperative that we choose the best fetal weight prediction model in order to ensure proper guide to the clinician to decide upon the proper care and intervention for better perinatal outcome. It has been noticed that the fetuses tend to gain weight in utero till the time of delivery, therefore various studies were conducted to find out the best time to document ultrasonically derived birth weight. In a recent study it was found that accurate estimation could be predicted if the fetal weight was calculated within 3 days of delivery. ${ }^{11}$ Therefore, this factor has also been accounted in this study and only deliveries within 3 days of last pre delivery Ultrasonography were included.

Various observations have been made to derive an ideal formula for the estimation of birth weight for different weight groups of infants. ${ }^{11-13}$ Parameters like cheek-to-cheek diameter, shoulder skin fold thickness were incorporated in estimating birth weight in macrosomic fetus. ${ }^{14}$ Soft tissue was included to aid in the prediction of birth weight and to correlate the fetal limb fat volume with neonatal parameters of fat. It was found that estimated fetal weight from 2D biometric measurements and the fractional thigh volume correlated with actual birth weight better than estimated fetal weight collected on the basis of traditional biometric measurements on 2D ultrasonography alone. ${ }^{15-17}$ The advantage of volumetric ultrasonography over conventional two-dimensional ultrasound is that reproducible circumference and volumetric measurements ease simultaneous visualization of three orthogonal fetal limb sections. The disadvantage however is that 3-D sonography is a technically demanding and a time-consuming process requiring advanced and expensive equipment with special operator training and skills and moreover, it may also be more difficult to apply during labor. It seems therefore unreasonable to adopt 3D over 2D ultrasound imaging for fetal weight estimation. MRI has been found to be promising than ultrasonography in estimating birth weight. ${ }^{18}$ Fetal weight was estimated in utero in eleven singleton pregnancies by measurement of fetal volume with echo-planar imaging (EPI), a form of magnetic resonance imaging, and by ultrasound measurements. EPI estimates of fetal volume were closely correlated with actual birth weight $(R=0.97)$. The median 
between actual and EPI-estimated birth weight was 3.0\% (range 0.6-9.9); this discrepancy was significantly smaller than that found for ultrasonographic estimates $(6 \cdot 5 \%$ [1.717.8]; $p<0.01) .{ }^{24}$ The ability to obtain multiplanar acquisitions and its theoretic improved resolution serves as the advantages of MRI compared with other imaging techniques. ${ }^{25}$ The disadvantage however, in addition to the expense, is the impracticability in collecting measurements during labour.

Birth weight estimation models derived from one ethnic population applied to another population might result in erroneous estimations. Studies have therefore been done in different places like Ireland, Australia, Iran, and China, to find whether the international ultrasound reference standards were appropriate for their population groups ${ }^{22} \mathrm{~A}$ comparative study done between Iranian and Australian fetuses found that the use of European or Australian standards was causing overestimation of expected fetal weight in growth retarded fetuses in Iranian population. ${ }^{18} \mathrm{~A}$ study done in Chinese population comparing use of Hadlock 1-4, Shepard, Wars of, Campbell and WOO 1 and 2 showed that Woo 2 model produced a better estimate of the actual birth weight with least difference in systematic bias and with acceptable limits of agreement ${ }^{19}$

It is observed in our study that there were no significant differences among all the formulae being studied; however, Hadlock2 which uses all the three parameters viz., Biparietal diameter (BPD), Femur length (FL) and Abdominal circumference (AC) showed better accuracy in fetal weight prediction than rest of the models in our population. This result favors similar results obtained by Hadlock using these parameters $^{20,21}$

\section{REFERENCES}

1. O'Reilley G, Divon M. Sonographic and clinical methods in the diagnosis of macrosomia. Clin Obstet Gynecol.2000; 43:309201.PMID:10863628

2. Vik T, Markestad T, Ahlsten $G$, et al. Body proportions and early neonatal morbidity in small-for-gestational-age infants of successive births. Acta Obstet Gynecol Scand Suppl.1997; 165:7681.PMID:9219462

3. Sack DA, Chen W. Estimating fetal weight in the management of macrosomia. Obstet Gynecol Surv. 2000; 55:229-39. PMID:10758619

4. Hendrix NW, Grandy CS, Chauhan SP. Clinical versus sonographic estimates of of birth weight in term parturients. A randomized clinical trail. J Reprod Med. 2000; 45: 317-22.PMID:10804488

5. Carol MR: Fetal measurements - normal and abnormal fetal growth In: Diagnostic ultrasound, 3rd ed. Mosby Publications; 2005:1462 78.

6. Hadlock FP, Harrist RB, Sharman RS, Deter RL, Park SK. Estimation of fetal weight with the use and head, body and femur measurements. Am J Obstet Gynecol. 1985; 151:333-7.PMID:3881966

7. Woo JS, Wan MC. An evaluation of fetal weight prediction using a simple equation containing the fetal femur length. J Ultrasound Med. Aug 1986; 5: 453-7.PMID: 3528524

\section{LIMITATION OF THE STUDY}

The limitations of this study are that the data collected was from a single center involving a small number of samples, which makes it difficult to generalize these results for the entire eastern region due to prevailing ethnicity difference. Very limited information is available in our country regarding the accuracy of various existing models. It is imperative therefore for further evaluation of existing ultrasonographybased fetal weight estimation models with well-designed prospective studies across the country and to derive a formula which will be better representative of the birth weight in our population

\section{CONCLUSION}

The mean birth weight recorded using Hadlock 1 formula gave the better correlation with the actual birth weight though the difference between four Hadlock formulae was all insignificant. All four Hadlock formulae were accurate within 200gms range of weight, but the best accuracy rate was observed for Hadlock 2 though the individual formulae were not stastically compared. Also, our study suggests that having multiple parameters does not necessarily result in a better accuracy of estimation. Hadlock 1 formula therefore seems to be promising in fetal weight prediction in our population.

\section{ACKNOWLEDGEMENT}

I would like to acknowledge all the respondents for their support, especially Dr. Nikesh Mani Rajbhandari for his help.

\section{CONFLICT OF INTEREST}

No conflict of interest to declare.

\section{FINANCIAL DISCLOSURE}

None.

8. Scioscia M, Vimercati A, Ceci O, Vicino M, Selvaggi LE. Estimation of fetal weight by two dimensional ultrasonography: a critical appraisal for its accuracy. J Obstet Gynecol. 2008; 111:57-65.DOI: 10.1097/01.AOG.0000296656.81143.e6PMID:18165393

9. Ratanasiri T, Jirapornkul S, Somboonporn W, Seejorn K, Patumnakul P. Comparison of the accuracy of ultrasonic fetal weight estimation by using the various equations. J Med Assoc Thai 2002; 85: 9627.PMID:12450073

10. Nahum GG, Stanislaw $H$. Ultrasonographic prediction of term birthweight: How accurate is it? Am J Obstet Gynecol. 2003; 188(2):556-74.PMID: 12592273

11. AB Haroush, Nir Melamed,Reuven Maschiach,Israel Meizner, Yariv Yogev.New Regression Formulas for Sonographic Weight Estimation within 10,7 , and 3 Days of Delivery.2008;27(11):155358.DOI:10.7863/jum.2008.27.11.1553

12. Kurmanavicius T, Burkhardt J, Wisser and R Huch. Ultrasonographic fetal weight estimation: accuracy of formulae and accuracy of examiners by birth weight from 500 to $5000 \mathrm{~g}$. J Perinatal Medicine 2004; 32(2): 155-61.DOI: 10.1515/JPM.2004.028

13. Melamed N, Yogev Y, Meizner I, Maschiach R, Haroush AB. Sonographic fetal weight estimation- Which model should be used? 2009; 28(5):617-29.PMID:19389901 
14. Abramowicz JS, Robischon K, Cox C. Incorporating sonographic cheek-to-cheek diameter, biparietal diameter and abdominal circumference improves weight estimation in the macrosomic fetus. Ultrasound Obstet Gynecol June 1997; 9(6):409-13.DOI: 10.1046/j.1469-0705.1997.09060409.x

15. Fadi RK, Brad S, Stephen AM, Brian M. Comparison of estimated fetal weights using volume and 2- dimensional sonography and their relationship to neonatal fat markers.JUM March 2009; 28(3): 309-15.DOI: 10.7863/jum.2009.28.3.309

16. Lee W, Balasubramaniam M, Deter RL, et al. Soft tissue parameters improve the precision of fetal weight estimation. Ultrasound Obstet Gynecol 2006; 28(suppl):389.DOI:10.1002/uog.7327

17. Lee W, Yao MJ, Deter RL, et al. Fetal soft tissue and birth weight: their relationship to newborn infant body composition. Ultrasound Obstet Gynecol 2006; 28(suppl): 473.

18. Niknafs $P$, Sibbald J. Are the international ultrasound reference standards appropriate for Iranian fetuses? Ultrasound Q 2001; 17(4): 261-6.PMID:12973067

19. Pang MW, Leung TN, Lau TK. A validation of ultrasonic fetal weight estimation models for Hong Kong Chinese singleton pregnancies. Hong Kong Med J 2004; 10(6): 384-8.PMID:15591596

20. Hadlock FP, Harrist RB, Sharman RS, Deter RL, Park SK. Estimation of fetal weight with the use and head, body and femur measurements. Am J Obstet Gynecol. 1985; 151: 333 - 7.PMID:3881966
21. Venkat A, Chinnaiya A, Gopal M, Mongelli JM. Sonographic fetal weight estimation in a south-east Asian population. J Obstet Gynecol Res Oct 2001; 27(5): 275-9.PMID:11776510

22. Lindell G, Marsal K. Sonographic fetal weight estimation in prolonged pregnancy: comparative study of two- and three-dimensional methods. Ultrasound Obstet Gynecol 2009; 33:295-300. DOI:10. 1002/uog.6281

23. Zretsky M, Reicheil TF, McIntire D, Twickler DM. Comparison of magnetic resonance imaging to ultrasound in estimation of birth weight at term. Am J Obstet Gynecol 2003; 189:101720.PMID:14586347

24. P.N Baker, I.R Johnson, P.A Gowland, et al.Fetal weight estimation by echo planar magnetic resonance imaging. The Lancet.1994; 343(8898):644-45.PMID: 7906814

25. Kubik-Huch RA, Wildermuth S, Cettuzzi L, et al. Fetus and uteroplacental unit: fast MR imaging with three-dimensional reconstruction and volumetry-feasibility study. Radiology 2001; 219:567-73.PMID:11323490.

26. Shripad H. Critical evaluation of various methods of estimating fetal weight by ultrasound. J Obstet Gynecol Ind. 2003; 53(2): 131-133.

27. Weiner CP, Sabbagha RE, Vaisurb N, Socol ML. Ultrasonic Fetal weight prediction: Role of head circumference and femur length. Am J Obstet Gynecol. 1985; 65(6): 812-817. PMID:3889747 